\title{
Import Substitution Production of Semiconductor Silicon in Russia as a Tool to Reduce the risk of Money Laundering
}

\section{Leonov P. Y., Kotelyanets O. S., and Ivanov N. V.}

National Research Nuclear University MEPhI (Moscow Engineering Physics Institute), Kashirskoe shosse 31, Moscow, 115409, Russia

\section{Abstract}

The work is devoted to studying the need of creation a domestic production of polycrystalline, monocrystalline silicon and silicon wafers for the purposes of electronics and solar energy in the Russian Federation, as a part of the solution of a number of strategic objectives. In addition, the work discusses the question of import substitution as a means of combating money-laundering.

Corresponding Author: Kotelyanets $0 . \mathrm{S}$. oksana_kot_1995@mail.ru Received: 11 December 2017 Accepted: 20 January 2018 Published: 13 February 2018 Publishing services provided by Knowledge E

(c) Leonov P. Y. et al. This article is distributed under the terms of the Creative Commons

Attribution License, which permits unrestricted use and redistribution provided that the original author and source are credited.

Selection and Peer-review under the responsibility of the FinTech and RegTech: Possibilities, Threats and Risks of Financial Technologies Conference Committee.
Keywords: semiconductor silicon, polycrystalline silicon, monocrystalline silicon, import substitution, money laundering

\section{Introduction}

The rapid development of microelectronics, primarily further miniaturization and complexity of integrated circuits, is linked to the development of innovative processes, the implementation of which is only possible using silicon wafers. The global semiconductor industry is dominated by the United States, South Korea, Japan, Taiwan, Singapore and the European Union [1]. The largest companies, which turnover exceeds 7000 million control \$50 per cent of the semiconductor industry market [2]. As the production of polycrystalline silicon is practically non-existent in Russia [3], the limited production of monocrystals is done by melting a semiconductor production waste, purchased in China and Europe. At the same time relatively high import volumes increase the risk of money laundering through kickbacks, corruption, «bloated» costs, etc.

The need to create a domestic production of polycrystalline, monocrystalline silicon and silicon wafers that are used for the purposes of electronics and solar energy (hereafter PS) is undeniable. Therefore, the search for opportunities for import substitution PS today is a pressing question requiring special attention both by the State and by 


\section{Analytical part}

Feature of the PS market is that only a few countries in the world have the possibility of its production, and corresponding technologies are not sold. Technologies of full-cycle PS production require sophisticated equipment. Complete technologies for production of semiconductor Silicon are now available only in the United States, Japan, Germany and Italy.

There are all preconditions for the re-establishment of full production of electronic products based on own PS in the Russian Federation today. Such assumptions include remained from the times of the Soviet Union school of materials science, including in the field of PS creation (special successes were achieved by using «Siemens-process», this method will be discussed below in detail), unsaturation of internal market with domestic products of electronic technology, the presence of the production sites with the necessary energy and transport infrastructure, qualified personnel and considerable experience in the development and operation of such productions.

For a number of years in JSC «Federal state research and design institute of raremetal industry «Giredmet» was carried out works on the improvement of the Russian Siemens-process technology and developing optimized, environmentally sound technology of polysilicon production, allowing to significantly reduce the rate of raw material, raw and auxiliary materials and energy. At the heart of modern technology of «Siemens-process» lies the use of recirculation technology with the ability to return to the main production of by-products and intermediate products or their implementation in the form of marketable products. Thus, a high level of ecological safety of production, optimum quality output of polycrystalline silicon and energy saving is achieved. On the way of getting a polycrystalline silicon and other technical decisions concerning technology for polysilicon are obtained patents of the Russian Federation.

Technological cluster of silicon wafers production from the feedstock, which is the metallurgical silicon, to finished products for the needs of electronics and solar energy is a complex technology production. Phases of Silicon transformations from breed to electronic products are presented on Figure 1. Production includes three main technological complexes:

1. Technological complex of high-purity polycrystalline silicon (PS) production.

2. The process of getting crystals and multi-crystal silicon blocks out of polycrystalline silicon. 


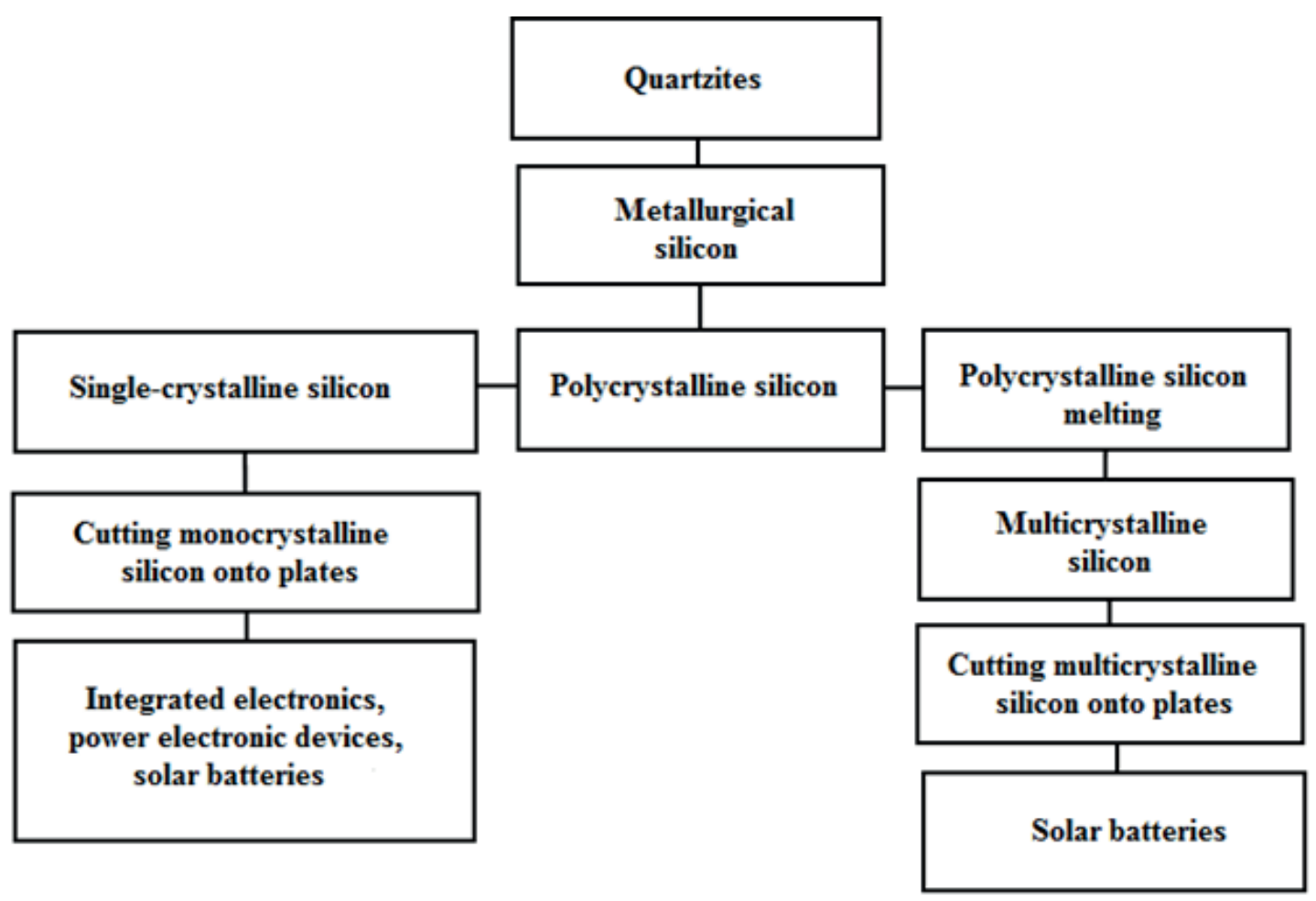

Figure 1: Siemens concept-process.

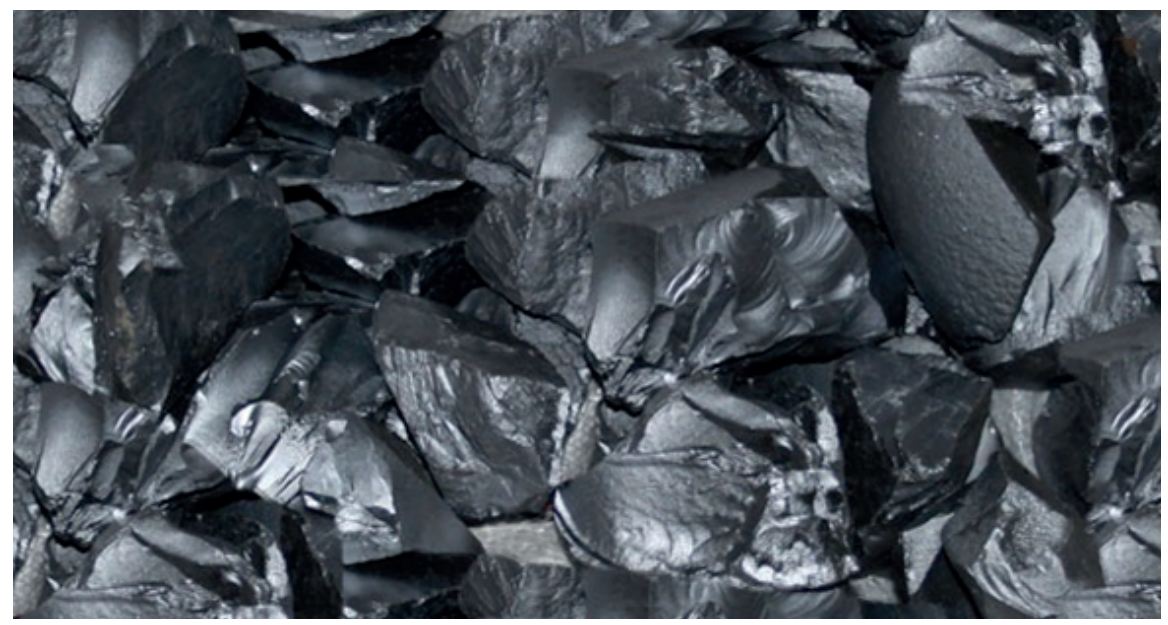

Figure 2: Sample of polycrystalline silicon after splitting the rods before packing.

3. Technological complex of cutting monocrystalline ingots and multicrystalline blocks on the plate, sanding and polishing plates [4].

Polycrystalline silicon of «e-quality» and «sunny» quality is the basis for the production of various discrete and integrated semiconductor devices and solar cells (fig. 2).

At work the obtaining of monocrystalline silicon (fig. 3 ) is provided by Czochralski growing process. 
Feedstock is polysilicon of own production, having previously splitting operation, is transported to plot layout of the priming. As an additional source of Silicon raw materials are used revolving Silicon material, defective silicon ingots, Silicon melt remnants of quartz crucibles, shards and trim plates. Weighted out and packed in a plastic bag, to which the required estimated number of dopant is attached, Silicon raw flows on the repartition of growing according Czochralski process.

The production of monocrystalline silicon consists of primary and secondary repartition industries. The project is based on the concept of an interconnected system of main and auxiliary equipment repartitions, united by automatically control system and ensures the complete cycle of cultivation and processing of ingots, control parameters, management and storage of products.

Apparatus-technological scheme of main production includes the following processes:

- preparation of raw materials;

- layout of the priming;

- single crystal growth;

- plot of reception and storage of bullion (PRSB);

- plot of chemical processing (PCP);

- plot a preliminary marking of ingots (PPMI);

- plot of machining (PM);

- plot of x-ray orientation (PXO);

- a plot of thermal processing (PTP);

- plot of parameters control and metrological assurance (PPCMA);

- automated warehouse system of repartition (AWS), which includes four sections:

1. section of the initial ingots;

2. section washers;

3. section speed;

4. section of the final product.

Auxiliary production includes:

- production of quartz crucibles;

- production of graphite parts for heaters [4]. 


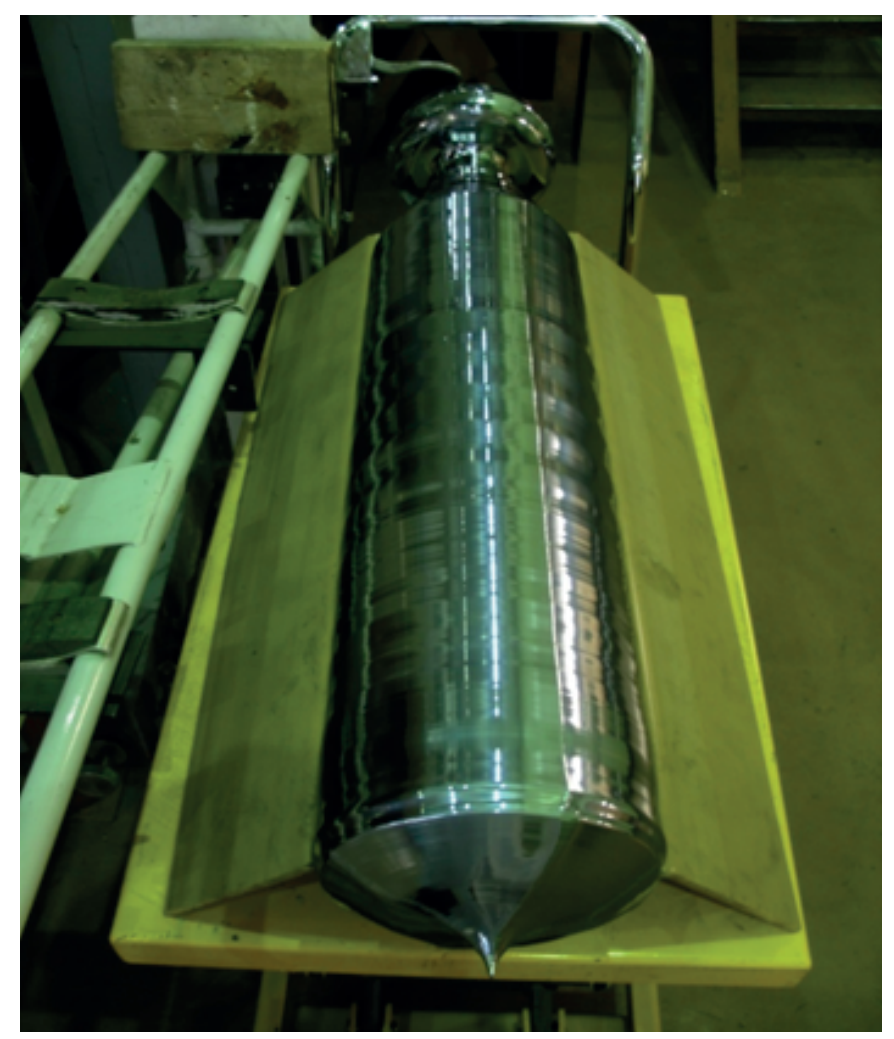

Figure 3: Sample of monocrystalline silicon.

Application monocrystalline silicon for the purposes of microelectronics or solar energy is defined by the dash structure of polycrystalline silicon source. The level of technology embodied in the project allows to respond flexibly to market needs, provide rapid turnover of products for specific customers. The final products of technological complex are:

- Monocrystalline plates polished $150 \mathrm{~mm}$ diameter for the electronics, $200 \mathrm{~mm}$ and $300 \mathrm{~mm}$ according to SEMI-compliant, with the total volume of production of 2500000 pieces per year.

- Monocrystalline plates for solar panels in the form of pseudo squares, made from bars $\varnothing 150 \mathrm{~mm}, \varnothing 200 \mathrm{~mm}$, the total volume of production of 60000000 $\mathrm{PCs} /$ year.

- Multicrystalline plates for solar panels in the form of pseudo squares, prepared from multicrystalline units, with the total volume of production of 42000000 $\mathrm{PCs} /$ year.

The production provides manufacturing of plates of multicrystalline Silicon blocks and plates of monocrystalline silicon ingots of pseudo square shape sized 156x156 $\mathrm{mm}$ thick $180-200 \mu \mathrm{m}$, used as substrates for creating high-performance solar cells. 
In accordance with emerging trends in the technology of production of solar cells it is possible to switch to the production of plates in the thickness $150-170$ microns and further decrease in the thickness of plates up to 80 microns.

Polished monocrystalline silicon wafers used as substrates in the Planar manufacturing techniques of semiconductor devices.

Thus, full-scale production in a single cluster along the chain from silicon to polycrystalline silicon wafers for the needs of electronics and solar energy in the Russian Federation will simultaneously solve a number of strategic objectives:

- create a material base for the recovery of the electronics industry;

- ensure the occurrence of domestic companies in the composition of the major producers of Silicon «electronic» and «sunny» quality for the needs of industry;

- intensify scientific and technological research in materials science, chemical engineering, metallurgy of semiconductors;

- raise level of economic Security of the country [5];

- intensify the training of specialists in the relevant fields.

With the right building and gradually developing policies of import substitution of PS the following significant advances in the field of Economics States can be achieved:

- make progress in science and technology, therefore, raise the level of education;

- reach and strengthen economic and military-industrial security of the country, thanks to the development of own PS manufacture;

- reduce the level of unemployment in the country due to the growth of employment, and as a result, improve the quality of life;

- stimulate demand for products of domestic production (semiconductor devices and solar cells).

Thus, import substitution is an important mean of preventing inflation, normalization of the internal market, combating unemployment.

In cases where the market has complete import dependence, issues of procurement fraud are often met.

Fraud can be made with the help of corruption. The special kind of the agreements and contracts relating to PS, complicates the understanding whether the company pays the real price for goods and services received, or the price is inflated as a result of corruption. In addition, funds transfers, aimed at reparation (compensation) of incurred 
costs on the formation of the Executive stock products required to fulfill the order are possible.

The consequences of such an act of corruption may be:

- violation of consumption patterns;

- corruption and bribery;

- reduction in the revenue of the public sector;

- artificial price increases;

- the distortion of economic statistics;

- impact on production, income and employment;

- changes in money demand, exchange rate and interest rates, etc.

In addition, money laundering can occur through:

- «kickbacks», i.e. the choice of a specific contract/company/offers and receive reward for this choice;

- the provision of very profitable contract to firm, which framed to the faces affiliate;

- transfer greater than necessary amounts, at the expense of the affiliate firm faces as payment for any goods/services, etc.

Taking into account the fact that the PS market in the Russian Federation is of fully import demand you can make the following conclusion: import substitution in the field of PS will reduce the risk of withdrawal from our country.

\section{Conclusion}

The survey referred to peculiarities of production of polycrystalline and monocrystalline silicon, has industry analysis, considering in some detail the process of production of high-purity polycrystalline silicon, technology complex of getting crystals and multi-crystal silicon blocks made of polycrystalline silicon, monocrystalline ingot cutting complex technology and multicrystalline blocks on the plate, sanding and polishing plates.

In addition, strategic tasks in the production of a PS are discussed. Moreover, the article shows the possible successes in the sphere of the State economy, with successful policies of import substitution boards. Also it addresses to the problem of moneylaundering through corruption violations, kickbacks, etc. 
In conclusion, we note that the import substitution of PS is necessary for the RF to reach the levels of leading semiconductor-producing countries, reduce potential risks in the area of money laundering, as well as to increase the level of economic security of the country.

\section{Acknowledgements}

This work was supported by Competitiveness Growth Program of the Federal Autonomous Educational Institution of Higher Education National Research Nuclear University MEPhl (Moscow Engineering Physics Institute).

\section{References}

[1] Encyclopedia. [Electronic resource]. URL : https://dic. academic. ru / dic. nsf / ruwiki $/ 1852049$

[2] Exchange Traded Funds [Electronic resource]. URL: https://alletf.ru/ analitycs/read/etf__poluprovodnikovoy_promyshlennosti/

[3] Edition of high technologies «(C) - news ». [Electronic resource]. URL : http://www. cnews. ru / news / top /2016-01-12 _ mirovoj _ rynok _ poluprovodnikov _ sokratilsya _na_2

[4] Official site of the Institute «Giredmet». [Electronic resource]. URL: http://www. giredmet.ru/ru/products/polysilicon/pulisilicontechnology/

[5] A.N. Zhukov, K.V. Evsikov, Leonov P.Y., Morozov N.V., Domashova J.V. Use of Data Mining Algorithms While Determining Threshold Values of Economic Security Indices. -2017 5th International Conference on Future Internet of Things and Cloud Workshops.-p. 20-24. 